\title{
Frontières
}

\section{La mort dans tous ses états}

\section{André Clément}

Volume 16, numéro 1, automne 2003

Remède ou poison?

URI : https://id.erudit.org/iderudit/1073753ar

DOI : https://doi.org/10.7202/1073753ar

Aller au sommaire du numéro

Éditeur(s)

Université du Québec à Montréal

ISSN

1180-3479 (imprimé)

1916-0976 (numérique)

Découvrir la revue

Citer ce document

Clément, A. (2003). La mort dans tous ses états. Frontières, 16(1), 4-4. https://doi.org/10.7202/1073753ar

Ce document est protégé par la loi sur le droit d'auteur. L'utilisation des services d'Érudit (y compris la reproduction) est assujettie à sa politique d'utilisation que vous pouvez consulter en ligne.

https://apropos.erudit.org/fr/usagers/politique-dutilisation/
Cet article est diffusé et préservé par Érudit.

Érudit est un consortium interuniversitaire sans but lucratif composé de l’Université de Montréal, l'Université Laval et l'Université du Québec à Montréal. Il a pour mission la promotion et la valorisation de la recherche. https://www.erudit.org/fr/ 


\title{
La mort dans tous ses états
}

\author{
André Clément, \\ professeur, École des arts visuels et médiatiques, UQÀM.
}

La philosophe américaine Susan Sontag avait déjà souligné, il y a plus de trente ans de cela, que toute image photographique exprimerait une certaine vision nostalgique du monde qui nous ramènerait inlassablement à l'idée de mortalité. Roland Barthes avait, lui aussi, souligné le caractère nostalgique des images photographiques en parlant du Ça a été: ce que l'on voit représenté dans l'image n'aura plus jamais lieu, cela est définitivement derrière nous. Mort de l'instant.

Certains rétorqueront qu'il est difficile de voir la mort évoquée dans les images récentes de Cindy Sherman, travestie en clown au grotesque sourire sur fond de dessins psychédéliques hypercolorés. Et pourtant, même dans des images qui semblent avoir été faites pour divertir par leur outrance ou qui confinent au burlesque, une certaine idée de la tragédie humaine et du caractère dérisoire de la vie apparaît.

Je crois que ce qui unit les images choisies pour ce numéro de la revue Frontières, c'est qu'elles expriment toutes une quête d'un certain rituel de la mort qui s'exprimerait non pas tant dans la représentation d'objets généralement associés aux rites funéraires, mais à travers une idée immanente de la notion de mortalité, de dégradation du vivant, comme si chaque objet, chaque feuille, chaque paysage représenté contenait en latence les données de sa propre disparition.

L'horizontalité de certaines images, comme celle intitulée Le tombeau de Saint-Michel (p. 28), fait expressément référence à la figure du gisant, même s'il n'y a aucune représentation de dépouille ou de cadavre. Parlons ici plutôt de cénotaphe d'un lieu. De même, dans l'image panoramique Paysage corrodé T/F (p. 90), l'évocation de l'idée de mort s'exprime ainsi par la superposition virtuelle d'images de nature très dissemblable : un fragment d'une peinture de Turner - le Turner presque aveugle des derniers jours - semble flotter sur un détail macroscopique de surface métallique rouillée. Dégradation entropique de la matière et effacement du visible se fusionnent et dialoguent ici de manière intuitive.

Le duo d'images Chronotome et Sphère (p. 58-59), pour sa part, propose une idée du passage du temps et de la globalité qui nous ramène à une vision cosmogonique du monde et de sa durée. Le cœur de la tranche d'arbre de Chronotome est constitué de mécanismes d'horlogerie désarticulés, pêlemêle, et ce chaos pourrait rappeler le dérèglement cellulaire qui induit inexorablement le vieillissement et l'état mortifère. Sphère, quant à elle, à partir de la prise de vue en plongée d'un simple tabouret d'atelier, par les meurtrissures qu'on y décèle, pourrait devenir une image radiographique du monde comme cellule en dégénérescence.

Les photographies « documentaires » d'objets ou d'installations industriels, comme Trophê, Jetée 1 et 2 ou Pelles (p. 53, 31, 32, 40), voudraient évoquer l'idée du monument ou de l'aménagement funéraire. En fait, au moment de la prise de vue, ces objets devenaient pour moi de tangibles symboles de notre passage éphémère en ce monde, des lieux et des objets de sépulture appartenant à une civilisation qu'une improbable archéologie aurait mis au jour. 